\title{
ON MAXIMAL CHAINS IN POSETS WITH GROUP ACTIONS
}

\author{
Abdul Aali J. Mohammad \& \\ Department of Mathematics \\ College of Education \\ University of Mosul
}

Received

15/11/2006

\author{
Department of Mathematics \\ College of Science \\ University of Kirkuk
}

Abbas H. Kathim

Accepted

21/02/2007

\section{الملهص}

هذفنا الرئيسي من هذا البحث درلسة للسلمل الظمى في بعض المجموء لت المرتب ـة جزئيا والتي عليها فعل زمرية ولاظنا ان هذه الدرلمة تعطينا بعض المؤثرات عن نوعية هذه الافعل . لذاسنحتاج اله درلسةسلوك أفعل الزمر على للسلمuل.

\section{ABSTRACT}

Our main purpose in this work is to study the maximal chains in group-posets to observe that this study gives us indications on the type of some group actions on posets. Therefore we shall study the behavior of the group actions on chains . 


\section{§.1 Introduction :}

For any group $\mathrm{G}$ and any set $\mathrm{X}$, we say that $\mathrm{G}$ acts on $\mathrm{X}$ from the left if to each $g \in G$ and $x \in X$ there corresponds a unique element in $X$ denoted by $\mathrm{g}_{\mathrm{X}}$ (or some times $\mathrm{gx}$ ) such that for all $\mathrm{x} \in \mathrm{X}$ and $\mathrm{g}_{1}, \mathrm{~g}_{2} \in \mathrm{G}$;

(i) ${ }^{e} x=x \quad$ (ii) ${ }^{g_{1}}\left(g_{2} x\right)=\left(g_{1} g_{2}\right) x$.

Such a set $\mathrm{X}$ with a left action of $\mathrm{G}$ on it, is called a left G-set, or simply a G-set. [13].

Since the concept of a group action of a group $\mathrm{G}$ on a set $\mathrm{X}$ began as a group homomorphism $\rho: \mathrm{G} \rightarrow \mathrm{S}_{1 \times 1}$, we can consider any element $\mathrm{g}$ in $G$ as a permutation $g: X \rightarrow X$ with $g(x)=g$ for all $x \in X$. So this concept can be extended on sets with additional mathematical structure, with $\rho: \mathrm{G} \rightarrow \mathrm{isom}(\mathrm{X}, \mathrm{X})$ and the isomorphism related to the structure on $\mathrm{X}$.

\section{§.2 Group-posets :}

In this section we give the definition of the group actions on posets. This definition is slightly different from the definition given in [5].

\section{Definition (2-1):}

Let $\mathrm{G}$ be a group and $\mathrm{P}$ a poset, we say that there is a left action of $\mathrm{G}$ on $\mathrm{P}$ if for every $\mathrm{g} \in \mathrm{G}$ and $\mathrm{p} \in \mathrm{P}$ there corresponds a unique element $g_{p} \in P$ such that for all $p, q \in P$ and $g, g_{1}, g_{2} \in G$;
(i) $\mathrm{e}_{\mathrm{p}}=\mathrm{p}$
(ii) $g_{2}\left(g_{1} p\right)=\left(g_{2} g_{1}\right) p$
(iii) if $\mathrm{p}\rangle \mathrm{q}$ then $\mathrm{g}_{\mathrm{p}\rangle} \mathrm{g}_{\mathrm{q}}$

Such a poset $P$ with a left action of $G$ on it, is called a left G-poset, (or simply a G-poset) . When condition (iii) is neglected, P is called a G-set . For more details see [7] , [9] and [10] .

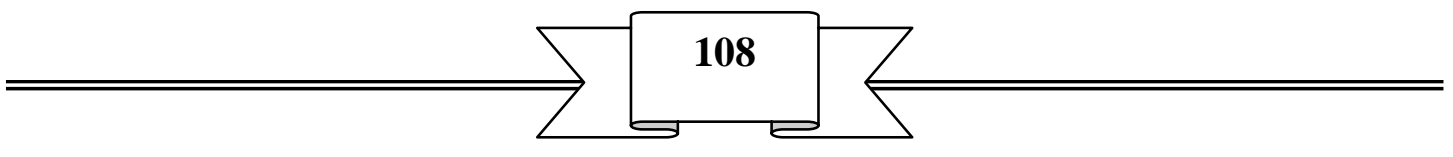




\section{Abdul Aali J. Mohammad \& Abbas H. Kathim}

Also, for any group $\mathrm{G}$ and poset $\mathrm{P}$ there is at least the trivial action which defined by : ${ }^{g} p=p$ for all $g \in G, p \in P$.

The following theorem shows that a group action on poset can be defined as a poset automorphism on P.

\section{Theorem (2-2) :}

Let $\mathrm{G}$ acts on the poset $\mathrm{P}$. Then to each $\mathrm{g} \in \mathrm{G}$ there corresponds an automorphism $\rho_{\mathrm{g}}$ on $\mathrm{P}$ defined by :

$\rho_{\mathrm{g}}(\mathrm{p})={ }^{\mathrm{g}} \mathrm{p}$ for all $\mathrm{p} \in \mathrm{P}$. Also, the map $\rho: \mathrm{G} \rightarrow$ Aut $(\mathrm{P})$; defined by $\rho(\mathrm{g})={ }^{\rho} \mathrm{g}$ for all $\mathrm{g} \in \mathrm{G}$ is a homomorphism called the corresponding homomorphism to the $\mathrm{G}$ action on $\mathrm{P}$.

\section{Proof:}

Similar to the proof in [9].

\section{Proposition (2-3) :}

Let $\mathrm{E}$ be a G-poset. Then $\mathrm{P}(\mathrm{E})$ the family of all subsets of $\mathrm{E}$ (the power set of $\mathrm{E}$ ) is a G-poset with an action defined by ; $\mathrm{g}_{\mathrm{Y}}=\left\{\mathrm{x} \in \mathrm{E}: \mathrm{g}^{-1} \mathrm{x} \in \mathrm{Y}\right\}$, for allg $\in \mathrm{G}$ and $\mathrm{Y} \in \mathrm{P}(\mathrm{E})$.

\section{Proof :}

(i) Let $\mathrm{Y} \in \mathrm{P}(\mathrm{E})$, then ${ }^{\mathrm{e}} \mathrm{Y}=\left\{\mathrm{x} \in \mathrm{E}: \mathrm{e}^{-1} \mathrm{x} \in \mathrm{Y}\right\}=\{\mathrm{x} \in \mathrm{E}: \mathrm{x} \in \mathrm{Y}\}=\mathrm{Y}$

(ii) For any $\mathrm{Y} \in \mathrm{P}(\mathrm{E})$ and $\mathrm{g}_{1}, \mathrm{~g}_{2} \in \mathrm{G}$;

$$
\begin{aligned}
g_{2}\left(g_{1} Y\right) & =\left\{x \in E: g_{2}^{-1} x \in g_{1} Y\right\}=\left\{x \in E: g_{1}^{-1}\left(g_{2}^{-1} x\right) \in Y\right\} \\
& \left.=\left\{x \in E: g_{1}^{-1} g_{2}^{-1} x \in Y\right\}=\left\{x \in E: g_{2} g_{1}\right)^{-1} x \in Y\right\}=\left(g_{2} g_{1}\right) Y .
\end{aligned}
$$

(iii) Let $X, Y \in P(E)$ with $Y>X$, and let $g \in G$. So $X \subset Y$, that is ${ }^{g} X \subset{ }^{g} Y$. Hence, ${ }^{g}{ }_{Y}>g_{X}$. Therefore $\mathrm{P}(\mathrm{E})$ is a G-poset.

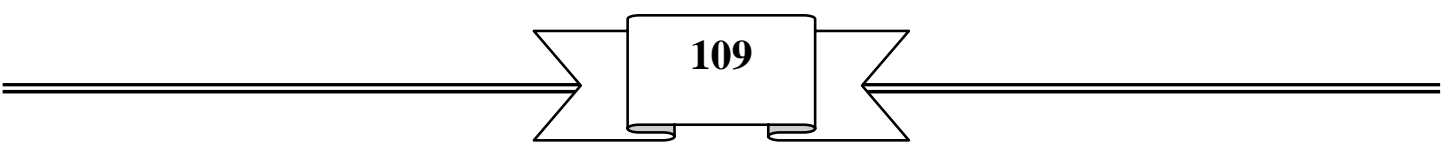


Definition (2-4): [16]

Let $P$ be a G-poset . For each $p \in P$, the set $\left\{g \in G: g_{p}=p\right\}$ is called the stabilizer of $p$ and denoted by $\operatorname{Stab}_{\mathrm{G}}(\mathrm{p})$ or $\mathrm{Gp}$.

Proposition (2-5) : [8]

Let $\mathrm{P}$ be a G-poset. Then for any $\mathrm{p} \in \mathrm{P}, \operatorname{Stab}_{\mathrm{G}}(\mathrm{p})$ is a subgroup of $\mathrm{G}$.

Proposition (2-6) :

Let $\mathrm{P}$ be a G-poset. Then for all $\mathrm{p} \in \mathrm{P}$.

(1) $\mathrm{G} / \mathrm{Stab}_{\mathrm{G}}(\mathrm{p})$ is a poset with ;

$g_{1} \cdot \operatorname{Stab}_{G}(p)>g_{2} \cdot \operatorname{Stab}_{G}(p)$ if and onlyif ${ }^{g_{1}}>g_{2} p$

(2) $G / \operatorname{Stab}_{G}(p)$ is a G-poset with an action defined by ;

${ }^{t}\left(g_{\cdot} \operatorname{Stab}_{G}(p)\right)=(\operatorname{tg}) \cdot \operatorname{Stab}_{G}(p)$ for all $t, g \in G$.

\section{Proof :}

(1)(i) It is obvious that the relation is reflexive .

(ii) Let $\mathrm{g}_{1} \cdot \operatorname{Stab}_{\mathrm{G}}(\mathrm{p}) \geq \mathrm{g}_{2} \cdot \operatorname{Stab}_{\mathrm{G}}(\mathrm{p})$ and $\mathrm{g}_{2} \cdot \operatorname{Stab}_{\mathrm{G}}(\mathrm{p}) \geq \mathrm{g}_{1} \cdot \operatorname{Stab}_{\mathrm{G}}(\mathrm{P})$.

Then ${ }^{g_{1}} p \geq g p$ and ${ }^{g_{2}} p \geq g_{1} p$. So $g_{1} p=g_{2} p$.

Hence $\mathrm{g}_{1} \cdot \operatorname{Stab}_{\mathrm{G}}(\mathrm{p})=\mathrm{g}_{2} \cdot \operatorname{Stab}_{\mathrm{G}}(\mathrm{p})$.

(iii) Let $g_{1} \cdot \operatorname{Stab}_{\mathrm{G}}(\mathrm{p}) \geq \mathrm{g}_{2} \cdot \operatorname{Stab}_{\mathrm{G}}(\mathrm{p})$ and $\mathrm{g}_{2} \cdot \operatorname{Stab}_{\mathrm{G}}(\mathrm{p}) \geq \mathrm{g}_{3} \cdot \operatorname{Stab}_{\mathrm{G}}(\mathrm{P})$.

Then ${ }^{g_{1}} p \geq g^{g_{2}} p$ and ${ }^{g_{2}} p \geq g^{g_{3}} p$. So ${ }^{g_{1}} p \geq g p$.

Hence $\mathrm{g}_{1} \cdot \operatorname{Stab}_{\mathrm{G}}(\mathrm{p}) \geq \mathrm{g}_{3} \cdot \operatorname{Stab}_{\mathrm{G}}(\mathrm{p})$.

Therefore $\left(G / \operatorname{stab}_{G}(p), \geq\right)$ is a poset.

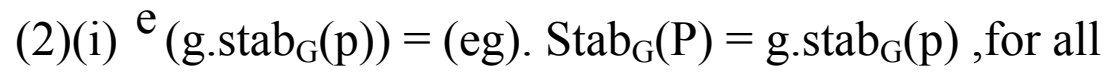
g.stab ${ }_{G}(p) \in G / \operatorname{Stab}_{G}(p)$.

(ii) Let g.stab $(\mathrm{s}) \in \mathrm{G} / \mathrm{Stab}_{\mathrm{G}}(\mathrm{p})$ and $\mathrm{t}, \mathrm{r} \in \mathrm{G}$. Then ;

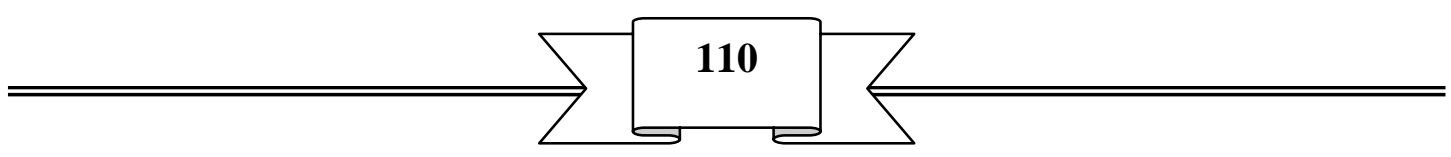




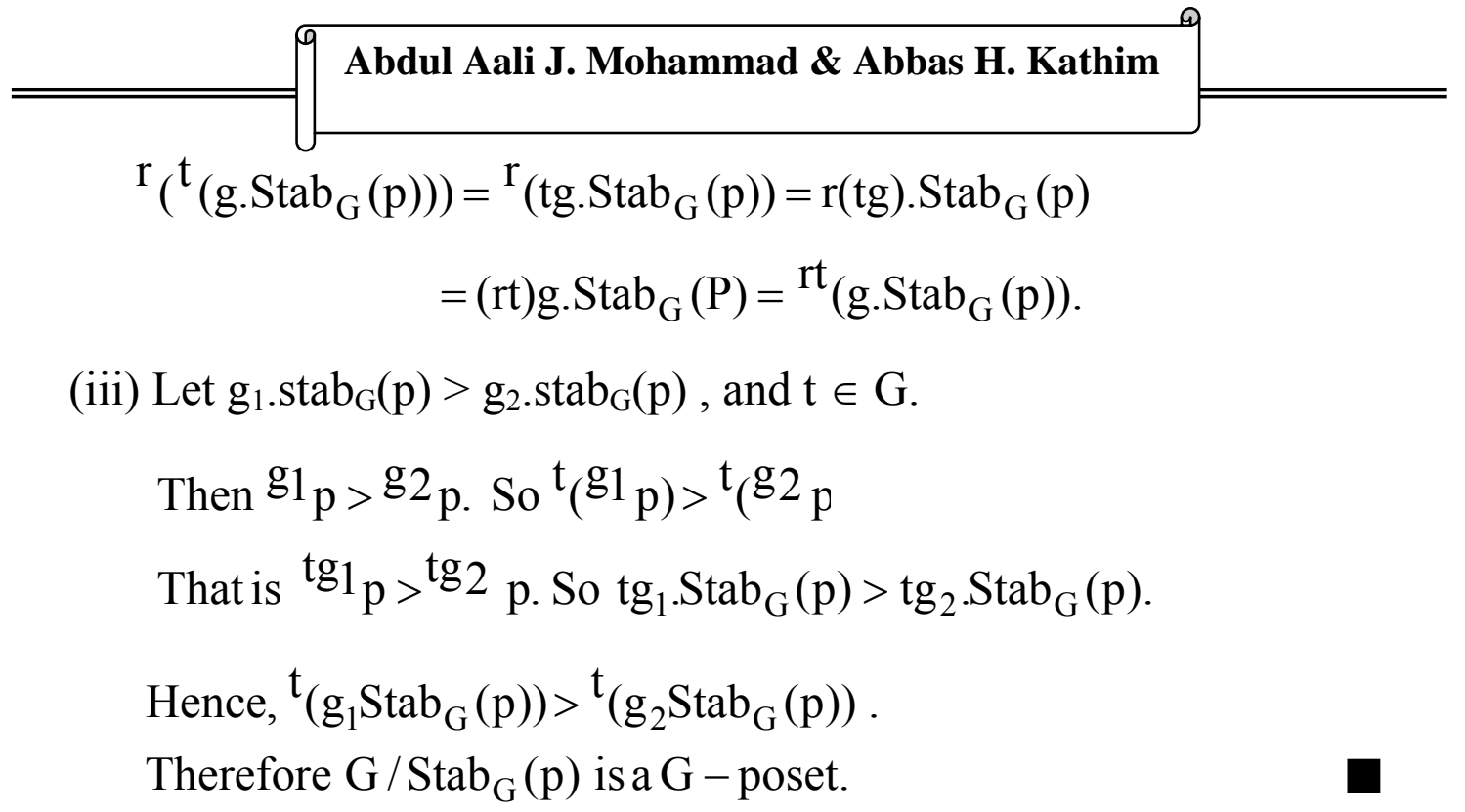

Definition (2-7) : [2]

Let $\mathrm{P}$ be a poset . We say that the element a of $\mathrm{P}$ covers the element $\mathrm{b}$ of $\mathrm{P}$ if $\mathrm{a}>\mathrm{b}$ and there is no element $\mathrm{c} \in \mathrm{P}$ such that $\mathrm{a}>\mathrm{c}>\mathrm{b}$.

\section{Proposition (2-8) :}

Let $\mathrm{P}$ be a G-poset and $\mathrm{a}, \mathrm{b} \in \mathrm{P}$ with a covers $\mathrm{b}$, then $\mathrm{g}_{\mathrm{a} \text { covers }} \mathrm{g}_{\mathrm{b}}$ for all $g \in \mathrm{G}$.

\section{Proof :}

Suppose that $\mathrm{g}_{\mathrm{a}}$ does not cover $\mathrm{g}_{\mathrm{p}}$, then there exist at least an element $c \in$ P such that $g_{a}>c>g_{b}$. So $g^{-1}\left(g_{a}\right)>g^{-1} c>g^{-1}\left(g_{b}\right)$. That is $g^{-1} g_{a>} g^{-1} c>g^{-1} g_{b}$. So $e_{a>} g^{-1} c>^{e} b$. Hence $a>g^{-1} c>b$ and this is a contruduction. Therefore $g_{a}$ covers $g_{b}$.

Definition (2-9) : [1]

Let $\mathrm{P}$ be a poset. Then the set, $\mathrm{C}(\mathrm{P})=\{(\mathrm{a}, \mathrm{b}): \mathrm{a}$ covers $\mathrm{b}\} \subset \mathrm{P} \times \mathrm{P}$, is called the covering poset of $\mathrm{P}$.

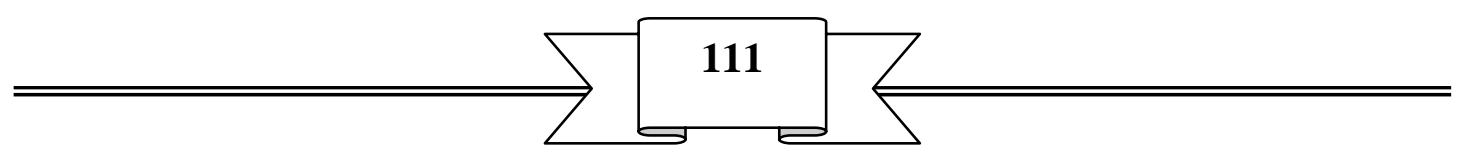


Proposition (2-10):

Let $(P, \geq)$ be a poset, then $((P), \geq)$ is a poset such that : for all $(a, b)$, $\left(a^{\prime}, b^{\prime}\right) \in C(P), \quad(a, b) \underset{C}{\geq}\left(a, b^{\prime}\right)$ if and onlyif $\left\{(a, b)=\left(a^{\prime}, b^{\prime}\right)\right.$ or $\left.b \geq a^{\prime}\right\}$

\section{Proof :}

(i) Let $(a, b) \in C(P)$, then $(a, b) \underset{c}{\geq}(a, b)$.

(ii) Let $(a, b) \underset{\mathrm{c}}{\geq}\left(a^{\prime}, b^{\prime}\right)$ and $\left(a^{\prime}, b^{\prime}\right) \underset{\mathrm{c}}{\geq}(a, b)$.

Then either; $(a, b)=\left(a^{\prime}, b^{\prime}\right)$, or $b \geq a^{\prime}$ and $b^{\prime} \geq a$.

Now sup pose that $b \geq a^{\prime}$ and $b^{\prime} \geq a$, then we have $a>b, b \geq a^{\prime}, a^{\prime}>b^{\prime}$ and $b^{\prime} \geq a$. So, $a>a$ and this is a contradiction. Hence it must be $(a, b)=\left(a^{\prime}, b^{\prime}\right)$.

(iii) Let $(a, b) \underset{\mathrm{c}}{\geq}\left(a^{\prime}, b^{\prime}\right)$ and $\left(a^{\prime}, b^{\prime}\right) \underset{\mathrm{C}}{\geq}\left(a^{\prime \prime}, b^{\prime \prime}\right)$.

Then either $(a, b)=\left(a^{\prime}, b^{\prime}\right)=\left(a^{\prime}, b^{\prime}\right)$, so $(a, b)=\left(a^{\prime \prime}, b^{\prime \prime}\right)$, or $b \geq a^{\prime}$ and $b^{\prime} \geq a^{\prime \prime}$.

So we have $b \geq a^{\prime}, a^{\prime}>b^{\prime}$ and $b^{\prime} \geq a^{\prime \prime}$. That is $b \geq a^{\prime \prime}$. Hence $(a, b) \underset{c}{\geq}\left(a^{\prime \prime}, b^{\prime \prime}\right)$

Therefore $\mathrm{C}(\mathrm{P})$ is a poset.

Theorem (2-11):

Let $\mathrm{P}$ be a G-poset. Then $\mathrm{C}(\mathrm{P})$ is also a G-poset with an action defined by; ${ }^{g}(a, b)=\left(g_{a},{ }^{g} b\right)$ for all $(a, b) \in C(P)$ and $g \in G$.

\section{Proof :}

(i) ${ }^{\mathrm{e}}(\mathrm{a}, \mathrm{b})\left({ }^{\mathrm{e}} \mathrm{a},{ }^{\mathrm{e}} \mathrm{b}\right)=(\mathrm{a}, \mathrm{b})$ for all $(\mathrm{a}, \mathrm{b}) \in \mathrm{C}(\mathrm{P})$.

(ii) $g_{1}\left(g_{2}(a, b)\right)=g_{1}\left(g_{2} a, g_{2} b\right)=\left(g_{1}\left(g_{2} a\right), g_{1}\left(g_{2} b\right)\right)$

$$
=\left(g_{1} g_{2} a, g_{1} g_{2} b\right)=g_{1} g_{2}(a, b)
$$

For all $(\mathrm{a}, \mathrm{b}) \in \mathrm{C}(\mathrm{P})$ and $\mathrm{g}_{1}, \mathrm{~g}_{2} \in \mathrm{G}$.

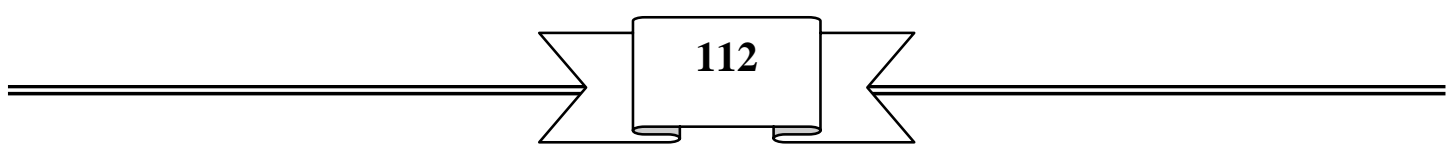


(iii) For all $(a, b),\left(a^{\prime}, b^{\prime}\right) \in C(P)$ and $g \in G$, with $\left(a^{\prime}, b^{\prime}\right) \underset{c}{>}(a, b)$.Then $b^{\prime} \geq a$

So $g_{b^{\prime} \geq} g$ a .Since $(a, b),\left(a^{\prime}, b^{\prime}\right) \in C(P)$. Then $\left(g_{a}, g_{b}\right),\left(g_{a^{\prime}}, g_{b^{\prime}}\right) \in C(P)$

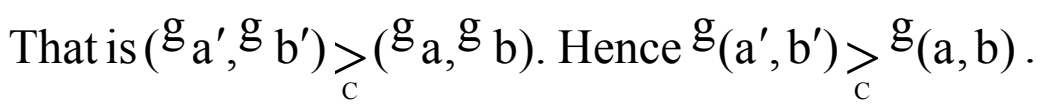

Therefore $\mathrm{C}(\mathrm{P})$ is a G-poset.

\section{§3. Group-Chains :}

In this section we study the group actions on chains and the behavior of these actions and when the trivial action is the only one.

Definition (3-1) : [2]

A poset $\mathrm{P}$ is called a chain (or totally ordered set) if : for all $\mathrm{a}, \mathrm{b} \in \mathrm{P}$ : $\mathrm{a} \geq \mathrm{b}$ or $\mathrm{b} \geq \mathrm{a}$.

Equivalently, the poset $\mathrm{P}$ is called a chain if for every two different elements $\mathrm{a}, \mathrm{b}$ of $\mathrm{P}$ either $\mathrm{a}>\mathrm{b}$ or $\mathrm{b}>\mathrm{a}$.

From the definition above, we conclude that every element of a chain covers at most one element and covered at most by one element . Also any chain has at most one maximal element I and one minimal element 0 .

Proposition (3-2) : [2]

Any chain $\mathrm{X}$ of $\mathrm{n}$ elements is isomorphic to the set of natural numbers $\underline{\mathrm{n}}=\{1,2, \ldots, \mathrm{n}\}$. That is there exists a bijection function $\mathrm{f}: \mathrm{X} \rightarrow \underline{\mathrm{n}}$ such that: $\mathrm{f}\left(\mathrm{x}_{1}\right) \geq \mathrm{f}\left(\mathrm{x}_{2}\right)$ if and only if $\mathrm{x}_{1} \geq \mathrm{x}_{2}$.

Theorem (3-3) :

Let $X=\left\{x_{i}\right\}_{i \in I}$ be a G-chain and I be a set of successive integers with $\ldots \mathrm{x}_{\mathrm{i}-1}<\mathrm{x}_{\mathrm{i}}<\mathrm{x}_{\mathrm{i}+1}<\ldots$

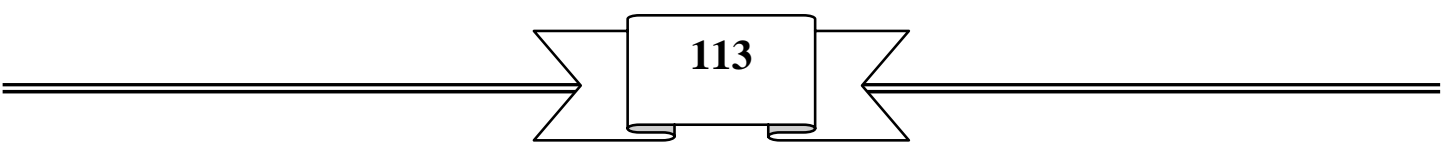


If $g_{x_{i}}=x_{j}$ then $g_{x_{i+r}}=x_{j+r}$ for all $i, j, i+r, j+r \in I$.

\section{Proof :}

(i) Let $i+1, j+1 \in I$. Since $X$ is a chain, then $x_{i+1}$ covers $x_{i}$ and by

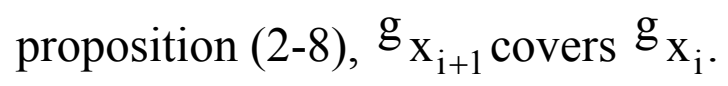

Since $g_{x_{i}}=x_{j}$, then $x_{j+1}$ covers $g_{x_{i}}$. So $g_{x_{i+1}}=x_{j+1}$.

(ii)Now we shall use the mathematical induction to prove that $g_{x_{i+r}}=x_{j+r}$. From (i) we see that $g_{x_{i+1}=x_{j+1}}$ for $r=1$. Suppose $\mathrm{g}_{\mathrm{x}_{\mathrm{i}+\mathrm{n}}}=\mathrm{x}_{\mathrm{j}+\mathrm{n}}$ for $\mathrm{r}=\mathrm{n}$ and $\mathrm{i}+\mathrm{n}, \mathrm{j}+\mathrm{n} \in \mathrm{I}$. Since $\mathrm{X}$ is a chain, then $x_{i+n+1}$ covers $x_{i+n}$. So $g_{x_{i+n+1}}$ covers $g_{x_{i+n}}$. Now from $g_{x_{i+n}}=g_{x_{j+n}}$ we have $\mathrm{g}_{\mathrm{x}_{\mathrm{i}+\mathrm{n}+1}}=\mathrm{x}_{\mathrm{j}+\mathrm{n}+1}$.

Therefore, $g_{x_{i+r}}=x_{j+r}$ for all $i, j, i+r, j+r \in I$.

Lemma (3-4) :

Let $X$ be a G-chain and $g \in G$. If $g_{x_{i}}=x_{t}$ and $x_{i}<x_{t}$ then $\mathrm{g}^{-1} \mathrm{x}_{\mathrm{i}}<\mathrm{x}_{\mathrm{i}}$ for all $\mathrm{x}_{\mathrm{i}} \in \mathrm{X}$.

\section{Proof :}

$\mathrm{g}_{x_{i}}=x_{t} \Rightarrow g^{-1}\left(g_{x_{i}}\right)=g^{-1} x_{t} \Rightarrow g^{-1} g x_{i}=g^{-1} x_{t} \Rightarrow g^{-1} x_{t}=x_{i}$.

Also , $x_{i}<x_{t} \Rightarrow g^{-1} x_{i}<g^{-1} x_{t}$. Therefore $g^{-1} x_{i}<x_{i}$.

Proposition (3-5) :

Let $X$ be a G-chain and $g \in G$ with $g^{-1}=g$. Then $g \in \operatorname{Stab}_{G}\left(x_{i}\right)$ for all $\mathrm{x}_{\mathrm{i}} \in \mathrm{X}$.

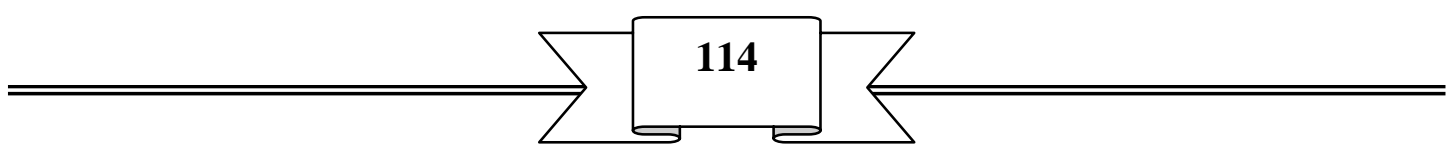




\section{Proof :}

Let $g_{x_{i}}=x_{t}$ Then $x_{i}=g^{-1} x_{t}$. So $x_{i}=g x_{t}$. Suppose that $x_{i} \neq x_{t}$.

Then either $\mathrm{x}_{\mathrm{i}}<\mathrm{x}_{\mathrm{t}}$ or $\mathrm{x}_{\mathrm{t}}<\mathrm{x}_{\mathrm{i}}$. If $\mathrm{x}_{\mathrm{i}}<\mathrm{x}_{\mathrm{t}}$ then $\mathrm{g}_{\mathrm{x}_{\mathrm{i}}}<\mathrm{g}_{\mathrm{t}}$. So, $\mathrm{x}_{\mathrm{t}}<\mathrm{x}_{\mathrm{i}}$. That is a contradiction. Similarly we have a contradiction if $x_{t}<x_{i}$.

Hence, since $X$ is a chain, then $x_{i}=x_{t}$. So, $g_{x_{i}}=x_{i}$. Therefore $\mathrm{g} \in \operatorname{Stab}_{\mathrm{G}}\left(\mathrm{x}_{\mathrm{i}}\right)$ for all $\mathrm{x}_{\mathrm{i}} \in \mathrm{X}$.

Theorem (3-6) :

Let $(\mathrm{X}, \leq)$ be a G-chain. Then the action of $\mathrm{G}$ on $\mathrm{X}$ is only the trivial action if $\mathrm{X}$ has 0 or $\mathrm{I}$.

\section{Proof :}

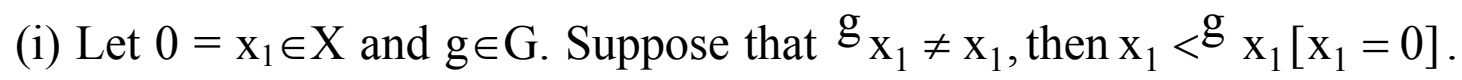
Also, $\mathrm{g}^{-1} \mathrm{x}_{\mathrm{i}}<\mathrm{x}_{1}=0$. So this is a contradiction . So, $\mathrm{g}_{\mathrm{x}_{1}}=\mathrm{x}_{1}$. Now from theorem (3-3) we have ${ }^{g} x_{i}=x_{i}$ for all $x_{i} \in X$ and $g \in G$.

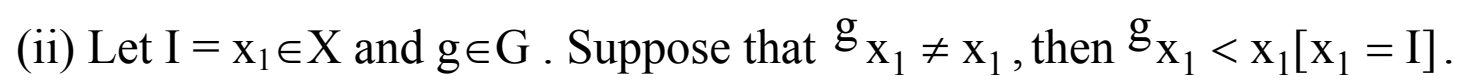
Also, $x_{1}<g^{-1} x_{1}$. So this is a contradiction .

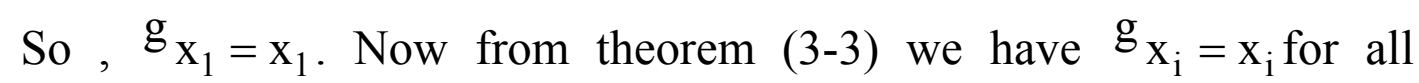
$\mathrm{X}_{\mathrm{i}} \in \mathrm{X}$ and $\mathrm{g} \in \mathrm{G}$.

The following corollary can be proved directly from the previous theorem, but we will give another proof.

\section{Corollary (3-7):}

Let $\mathrm{P}=\left\{\mathrm{p}_{1}, \mathrm{p}_{2}, \ldots, \mathrm{p}_{\mathrm{n}}\right\}$ be a G-chain with $\mathrm{p}_{1}>\mathrm{p}_{2}>\ldots>\mathrm{p}_{\mathrm{n}}$. Then $\mathrm{P}$ is a trivial G-chain.

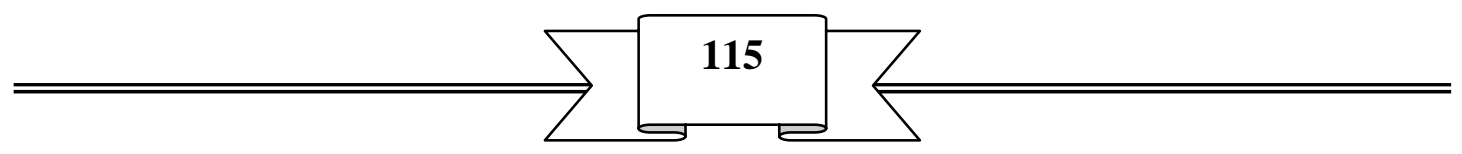




\section{Proof :}

Suppose that there exists $g \in G$ and $p_{i} \in P$ such that ${ }^{g} p_{i}=p_{t}$ with $t \neq i$ . That is ${ }^{g} p_{i} \neq p_{t}$. Suppose that $t>i$, then $g_{p_{i+(n-t)}}=p_{t+(n-t)}=p_{n}$ such that $\mathrm{i}+(\mathrm{n}-\mathrm{t}) \in\{1,2, \ldots, n\} . \quad$ Also, $\quad \mathrm{g}_{\mathrm{p}_{\mathrm{i}+(\mathrm{n}-\mathrm{t})+1}=\mathrm{p}_{\mathrm{n}+1} \text { such that }}$

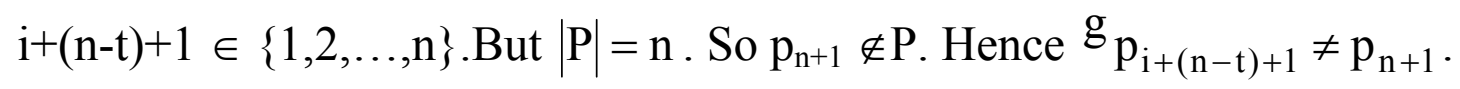

Now let $g_{p_{i+(n-t)+1}}=p_{r}$. Since $\quad p_{i+(n-t)}>p_{i+(n-t)+1}$, then $\mathrm{g}_{\mathrm{p}_{\mathrm{i}+(\mathrm{n}-\mathrm{t})}}>\mathrm{g} \mathrm{p}_{\mathrm{i}+(\mathrm{n}-\mathrm{t})+1}$. So, $\mathrm{p}_{\mathrm{n}}>\mathrm{p}_{\mathrm{r}}$ and this is a contradiction. Similarly we have contradiction when $t<i$. Hence $t=i$.

Therefore the $\mathrm{G}$ action on $\mathrm{P}$ is the trivial action only.

\section{§.4 Maximal chains :}

Finally in this section we will study the maximal chains in group-posets and we shall observe that the study of these kinds of chains give us some indications on the type of some group actions on posets.

Definition (4-1) : [3]

Let $\mathrm{P}$ be a poset and $\mathrm{X}=\left\{\mathrm{x}_{\mathrm{i}}, \mathrm{x}_{\mathrm{i}+1}, \ldots, \mathrm{x}_{\mathrm{j}}\right\} \subseteq \mathrm{P}$ be a chain such that $\mathrm{x}_{\mathrm{i}}<\mathrm{x}_{\mathrm{i}+1}<\ldots<\mathrm{x}_{\mathrm{j}}$, then $\mathrm{X}$ is called a maximal chain in $\mathrm{P}$ if and only if :

(i) There is no element as $\mathrm{c} \in \mathrm{P}$ such that : $\mathrm{x}_{\mathrm{i}}<\mathrm{x}_{\mathrm{i}+1}<\ldots<\mathrm{c}<\ldots<\mathrm{x}_{\mathrm{j}}$.

(ii) There is no element as $\mathrm{k} \in \mathrm{P}$ such that: $\mathrm{k}<\mathrm{x}_{\mathrm{i}}$ or $\mathrm{x}_{\mathrm{j}}<\mathrm{k}$.

Proposition (4-2):

Let $\mathrm{P}$ be a G-poset and $\mathrm{Y}$ be a maximal chain in $\mathrm{P}$. Then ${ }^{\mathrm{g}} \mathrm{Y}$ is also a maximal chain in $\mathrm{P}$ with $\left|\mathrm{g}_{\mathrm{Y}}\right|=|\mathrm{Y}|$.

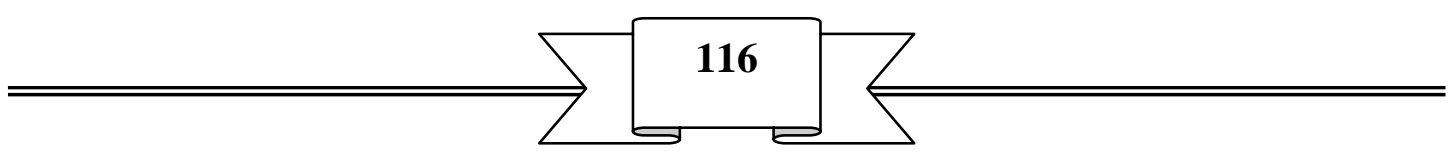




\section{Proof:}

(i) Since $\mathrm{Y}$ is a maximal chain in $\mathrm{P}$, so we can say $\mathrm{Y}=\left\{\mathrm{x}_{\mathrm{i}}, \mathrm{x}_{\mathrm{i}+1}, \ldots, \mathrm{x}_{\mathrm{j}}\right\}$ such that $x_{r+1}$ is covers $x_{r}$ for all $i<r<j$. So, $g_{Y}=\left\{g_{x_{i}}, g_{x_{i+1}, \ldots,}{ }^{g} x_{j}\right\}$ for all $g \in G$. Hence $g_{x_{i}}<{ }^{g} x_{i+1}<\ldots<g x_{j}$. Suppose that there exists an

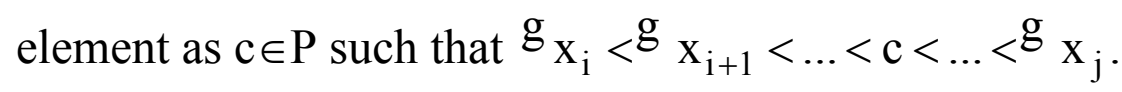

Then $\mathrm{g}^{-1}\left(\mathrm{~g}_{\mathrm{x}_{\mathrm{i}}}\right)<\mathrm{g}^{-1}\left(\mathrm{~g}_{\mathrm{x}_{\mathrm{i}+1}}\right)<\ldots<\mathrm{g}^{-1} \quad \mathrm{c}<\ldots<\mathrm{g}^{-1}\left(\mathrm{~g}_{\mathrm{x}_{\mathrm{j}}}\right)$.

That is $\mathrm{x}_{\mathrm{i}}<\mathrm{x}_{\mathrm{i}+1}<\ldots<\mathrm{g}^{-1} \mathrm{c}<\ldots<\mathrm{x}_{\mathrm{j}}$ and this is a contradiction since $\mathrm{Y}$ is a maximal chain.

(ii) suppose that there exists an element $\mathrm{b} \in \mathrm{P}$ such that $\mathrm{b} \leq^{\mathrm{g}} \mathrm{x}_{\mathrm{i}}$ then :

$\mathrm{b} \leq \mathrm{g}_{\mathrm{x}_{\mathrm{i}}} \Rightarrow \mathrm{g}^{-1} \mathrm{~b} \leq \mathrm{x}_{\mathrm{i}} \Rightarrow \mathrm{g}^{-1} \mathrm{~b}=\mathrm{x}_{\mathrm{i}} \Rightarrow \mathrm{b}=\mathrm{g}_{\mathrm{x}_{\mathrm{i}}}$. Similarly,if $\mathrm{g}_{\mathrm{x}_{\mathrm{j}}} \leq \mathrm{a}$ then

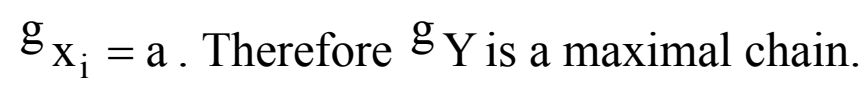

Now let the map $f: Y \rightarrow^{g} Y$ is defined by $: f(y)={ }^{g}$ y for all $y \in Y$.

$\mathrm{f}$ is injective map since : $\mathrm{f}\left(\mathrm{y}_{1}\right)=\mathrm{f}\left(\mathrm{y}_{2}\right) \Rightarrow \mathrm{g}_{\mathrm{y}_{1}}=\mathrm{g}_{\mathrm{y}_{2}} \Rightarrow \mathrm{y}_{1}=\mathrm{y}_{2}$.

Also $f$ is onto since if $x \in \in^{g} Y$ then there exits $y \in Y$ such that $\mathrm{x}=\mathrm{g} \mathrm{y}$. Hence, $\mathrm{f}$ is bijection and $|\mathrm{Y}|=|\mathrm{g} \mathrm{Y}|$.

Definition (4-3) : [4]

Let $\mathrm{P}$ be a poset and $\mathrm{x} \in \mathrm{P}$. Then the subset $\mathrm{C}$ of $\mathrm{P}$ is called a cutset of the element $\mathrm{x}$ in $\mathrm{P}$ if every element of $\mathrm{C}$ is not comparable with $\mathrm{x}$ and all the maximal chains in $\mathrm{P}$ cut with $\mathrm{C} \cup\{\mathrm{x}\}$. We shall note to this set by cut $x$.

Theorem (4-4) :

Let $\mathrm{P}$ be a G-poset and $\mathrm{C}$ is the cutset of $\mathrm{x} \in \mathrm{P}$. Then ${ }^{\mathrm{g}} \mathrm{C}$ is the cutset of $g_{X}$. That is $g_{C=c u t} g_{X}$.

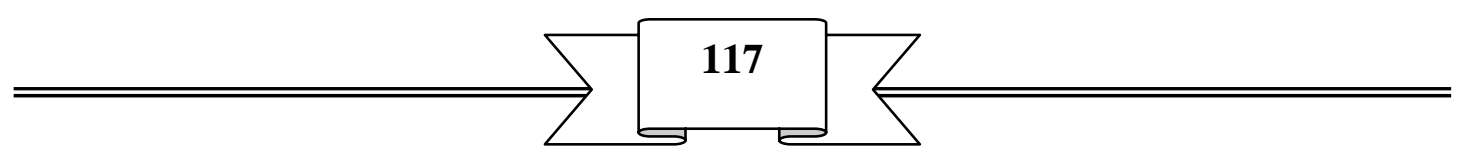




\section{Proof :}

Let $y \in$ cut $^{g} x$ then ${ }^{-1} y$ is not comparable with ${ }^{g} x$. So $g^{-1} y$ is not

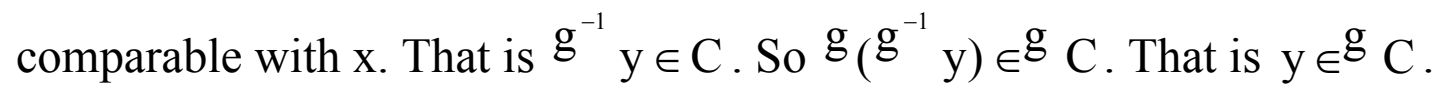
Hence cut ${ }^{\mathrm{g}} \subset^{\mathrm{g}} \mathrm{C}$.

Now let $g_{\mathrm{S} \in} \mathrm{g}$. Then $\mathrm{s} \in \mathrm{C}$. So $\mathrm{s}$ in not comparable with $\mathrm{x}$. That is $g_{\mathrm{S}}$ is not comparable with $\mathrm{g}_{\mathrm{x}}$. So $\mathrm{g}_{\mathrm{S} \in \text { cut }} \mathrm{g}_{\mathrm{X}}$. Therefore $\mathrm{g}_{\mathrm{C}=\text { cut }} \mathrm{g}_{\mathrm{X}}$

Theorem (4-5) :

Let $P$ be a finite G-poset with $P(M)=\left\{M_{1}, M_{2}, \ldots, M_{n}\right\}$ be the set of the maximal chains in $P$ with $\left|M_{i}\right|=\left|M_{j}\right|$ if and only if $i=j$. Then the trivial action is the only action of $\mathrm{G}$ on $\mathrm{P}$.

\section{Proof :}

To prove this theorem we must first prove that $g_{M_{i}}=M_{i}$ for $1 \leq \mathrm{i} \leq \mathrm{n}$, after that we must show that $\mathrm{g}_{\mathrm{x}}=\mathrm{x}$ for all $\mathrm{x} \in \mathrm{M}_{\mathrm{i}}$ and $\mathrm{g} \in \mathrm{G}$

\section{First part :}

Our argument proceeds by induction on the number $\mathrm{n}$ to prove that $\mathrm{g}_{\mathrm{M}_{\mathrm{i}}}=\mathrm{M}_{\mathrm{i}}$ for all $1 \leq \mathrm{i} \leq \mathrm{n}$.

Let $\left|M_{1}\right|=r_{1},\left|M_{2}\right|=r_{2}, \ldots,\left|M_{n}\right|=r_{n}$ such that $r_{1}<r_{2}<\ldots<r_{n}$.

(i) Let $\mathrm{n}=2$. That is $\mathrm{P}(\mathrm{M})=\left\{\mathrm{M}_{1}, \mathrm{M}_{2}\right\}$ with $\left|\mathrm{M}_{1}\right| \neq\left|\mathrm{M}_{2}\right|$.

Suppose that $\mathrm{g}_{\mathrm{M}_{1}} \neq \mathrm{M}_{1}$, then $\mathrm{g}_{\mathrm{M}_{1}}=\mathrm{M}_{2}$. So $\left|\mathrm{g}_{\mathrm{M}_{1}}\right|=\left|\mathrm{M}_{2}\right|=\left|\mathrm{M}_{1}\right|$ and this is a contradiction. Hence ${ }^{g} M_{1}=M_{1}$. Similarly we have $g_{M_{2}}=M_{2}$. (ii) Now assume that $\mathrm{n}=\mathrm{k}$ with ${ }^{\mathrm{g}} \mathrm{M}_{\mathrm{i}}=\mathrm{M}_{\mathrm{i}}$ for all $1 \leq \mathrm{i} \leq \mathrm{k}$.

Let $\mathrm{n}=\mathrm{k}+1$. Since $\mathrm{g}_{\mathrm{M}_{\mathrm{i}}}=\mathrm{M}_{\mathrm{i}}$ for all $1 \leq \mathrm{i} \leq \mathrm{k}$.

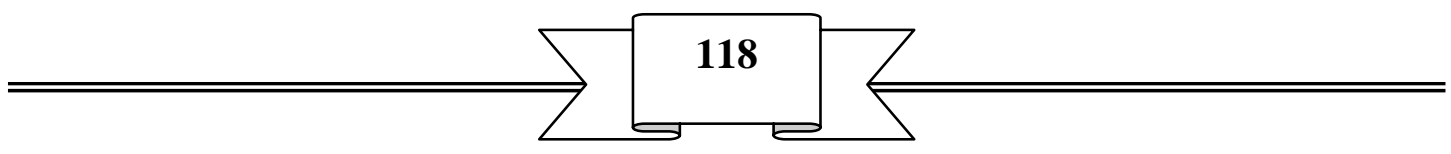


Suppose that $\mathrm{g}_{\mathrm{M}_{\mathrm{k}+1}} \neq \mathrm{M}_{\mathrm{k}+1}$ then $\mathrm{g}_{\mathrm{M}_{\mathrm{k}+1}}=\mathrm{M}_{\mathrm{j}}$ for some $1 \leq \mathrm{j} \leq \mathrm{k}$. So $\left|g_{M_{k+1}}\right|=\left|M_{j}\right|=r_{j}$. But $\left|g_{M_{k+1}}\right|=\left|M_{k+1}\right|=r_{k+1}$. Hence $r_{j}=r_{k+1}$, that is $\mathrm{j}=\mathrm{k}+1$, and this is a contradiction since $\mathrm{k}+1>\mathrm{j}$. So $\mathrm{g}_{\mathrm{M}_{\mathrm{k}+1}}=\mathrm{M}_{\mathrm{k}+1}$.

\section{Second part:}

Since $\left\{\mathrm{Mi}_{\mathrm{i}_{1=1}^{\mathrm{n}}}^{\mathrm{n}}\right.$ is the family of the maximal chains in $\mathrm{P}$, the $\mathrm{M}_{\mathrm{i}}$ is a finite maximal chain in P. Using corollary (3-7) we get : $g_{x}=x$ for all $\mathrm{x} \in \mathrm{M}_{\mathrm{i}}, \mathrm{g} \in \mathrm{G}$ with $1 \leq \mathrm{i} \leq \mathrm{n}$.

Therefore from part one, the action of $G$ on $P$ is the trivial action only.

The above theorem is not true when $P$ has two maximal chains $M_{i}, M_{j}$ with $\left|\mathrm{M}_{\mathrm{i}}\right|=\left|\mathrm{M}_{\mathrm{j}}\right|$ as in the following example .

Example (4-6):

Let $\mathrm{P}=\{\mathrm{a}, \mathrm{b}, \mathrm{c}, \mathrm{d}\}$ be $\mathrm{a}$ poset with $\mathrm{a}>\mathrm{b}$ and $\mathrm{c}>\mathrm{d}$. So $\mathrm{P}(\mathrm{M})=\left\{\mathrm{M}_{1}, \mathrm{M}_{2}: \mathrm{M}_{1}=\{\mathrm{a}, \mathrm{b}\}, \mathrm{M}_{2}=\{\mathrm{c}, \mathrm{d}\}\right\}$. Hence $\left|\mathrm{M}_{1}\right|=\left|\mathrm{M}_{2}\right|$.

Let $\mathrm{G}=\mathrm{C}_{2}=\{\mathrm{e}, \mathrm{g}\}$ with $\mathrm{g}^{2}=\mathrm{e}$, and $\mathrm{g}_{\mathrm{a}=\mathrm{c}},{ }^{\mathrm{g}} \mathrm{b}=\mathrm{d}$.

Therefore $\mathrm{P}$ is a G-poset and the action is not trivial .

Proposition (4-7):

Let $P(M)=\left\{M_{1}, M_{2}, \ldots, M_{n}\right\}$ be the set of the maximal chains in the G-poset P. Let ${ }^{g} M_{i}=M_{t}$, then ${ }^{g} M_{j} \neq M_{t}$ for all $j \neq i$.

\section{Proof :}

Suppose that $\mathrm{g}_{\mathrm{M}_{j}}=\mathrm{M}_{\mathrm{t}}$ for some $\mathrm{j} \neq \mathrm{i}$. Then $\mathrm{g}_{\mathrm{M}_{j}}=\mathrm{g}_{\mathrm{M}_{\mathrm{i}}}$ for some $j \neq i$. So $g^{-1}\left(g_{M_{j}}\right)=g^{-1}\left(g_{M_{i}}\right)$ for some $j \neq i$.

Hence $M_{j}=M_{i}$ for some $j \neq i$. This is a contradiction since $j \neq i$ implies $|P(M)|<n$. Therefore ${ }^{g} M_{j} \neq M_{t}$ for all $j \neq i$.

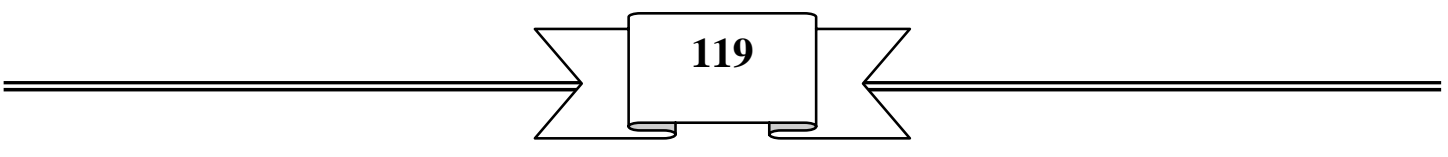


Proposition (4-8) :

Let $\mathrm{P}$ be an injective G-poset, and $\mathrm{P}(\mathrm{M})=\left\{\mathrm{M}_{1}, \mathrm{M}_{2}, \ldots, \mathrm{M}_{\mathrm{n}}\right\}$ be the family of the maximal chains in $\mathrm{P}$. Then :

(i) $\left(\left|\mathrm{M}_{\mathrm{i}}\right|=\left|\mathrm{M}_{\mathrm{j}}\right|\right.$ if and only if $\left.\mathrm{i}=\mathrm{j}\right)$, implies that $\mathrm{G}=\{\mathrm{e}\}$.

(ii) If $\left|M_{1}\right|=\left|M_{2}\right|=\ldots=\left|M_{n}\right|$, then $|G| \leq n$ !.

(iii) If we reordered the maximal chains such that :

$\left|\mathrm{N}_{1}\right|=\left|\mathrm{N}_{2}\right|=\ldots=\left|\mathrm{N}_{\mathrm{r}}\right| \neq\left|\mathrm{N}_{\mathrm{r}+1}\right|=\ldots=\left|\mathrm{N}_{\mathrm{t}}\right| \neq\left|\mathrm{N}_{\mathrm{t}+1}\right|=\ldots=\left|\mathrm{N}_{\mathrm{n}}\right|$, with $\mathrm{N}_{\mathrm{i}} \in \mathrm{P}(\mathrm{M})$, $1 \leq \mathrm{i} \leq \mathrm{n}$, then : $|\mathrm{G}| \leq \mathrm{r} ! \mathrm{x}(\mathrm{t}-\mathrm{r})$ ! $\mathrm{x} . . \mathrm{x}(\mathrm{n}-\mathrm{k})$ ! .

\section{Proof :}

(i) Since $\left.\rho(\mathrm{g})=\rho_{\mathrm{g}}\right)(\mathrm{p})=\mathrm{p}=\mathrm{I}(\mathrm{p})$ for all $\mathrm{p} \in \mathrm{P}, \mathrm{g} \in \mathrm{G}$, then $\mathrm{g} \in \operatorname{ker}(\rho)$. $\operatorname{But} \operatorname{ker}(\rho)=\{\mathrm{e}\}$ because $\rho$ is injective .

Then $\mathrm{g}=\mathrm{e}$ for all $\mathrm{g} \in \mathrm{G}$. So $\mathrm{G}=\operatorname{ker}(\rho)=\{\mathrm{e}\}$.

(ii) $\left|M_{1}\right|=\left|M_{2}\right|=\ldots=\left|M_{n}\right|$. So for all $M_{i} \in P(M)$ and $g \in G$ there exists some $\mathrm{M}_{\mathrm{t}} \in \mathrm{P}(\mathrm{M})$ such that $\mathrm{g}_{\mathrm{M}_{\mathrm{i}}}=\mathrm{M}_{\mathrm{t}}$. From proposition (4-7) we have $g_{M_{i}} \neq M_{t}$ for all $j \neq i$.

So the Number of permutations on the maximal chains is $n$ !.

Now since $P$ is an injective G-poset, then $|G| \leq n$ ! .

(iii) Applying (ii) on every part of equal parts of :

$\left|\mathrm{N}_{1}\right|=\left|\mathrm{N}_{2}\right|=\ldots=\left|\mathrm{N}_{\mathrm{r}}\right| \neq\left|\mathrm{N}_{\mathrm{r}+1}\right|=\ldots=\left|\mathrm{N}_{\mathrm{t}}\right| \neq\left|\mathrm{N}_{\mathrm{t}+1}\right|=\ldots \neq\left|\mathrm{N}_{\mathrm{k}+1}\right|=\ldots=\left|\mathrm{N}_{\mathrm{n}}\right|$ we get that the number of permutations on the equal parts are, $\mathrm{r} !,(\mathrm{t}-\mathrm{r}) !, \ldots,(\mathrm{n}-\mathrm{k})$ ! respectively . Using the fundamental principle of counting, the number of the permutations on the maximal chains is $\mathrm{r} ! \mathrm{x}(\mathrm{t}-\mathrm{r})$ ! x ... x(n-k)! .

Since $P$ is an injective G-poset, then $|G| \leq r$ ! $x(t-r)$ ! x .. x (n-k)! .

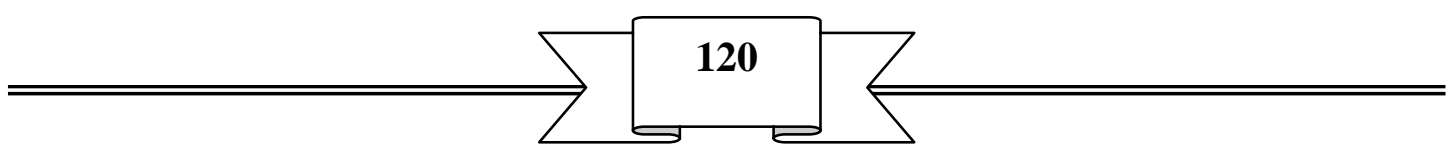




\section{REFERENCES}

[1] Behrendt. Gerhard, "Covering Poset" Discrete Math. 71. No.3, (1988), 189-195.

[2] Birkhoff G., "Lattice Theory", Amer. Math. Soc. Coll. Pub. Vol. XXV, Third Edition, (1967).

[3] Donnellant T., "Lattice Theory", Pergamon Press, (1968).

[4] Hanlon P., "The Incidence Algebra of a Group Reduced Partially Order Set" Combinatorial Math. 7, Sprnger. No.829.

[5] Mohammad A.J. \& Mohammad S.A. “ $\beta$-operations on Finite Posets”, J. Edu. \& Sci., Vol. 19, (1994), 104-114.

[6] Mohammad A.J. \& Mohammad S.A. "On Finite, Group-Sets of Finite Groups", J. Edu. \& Sci., Vol.22, (1994), 78-84.

[7] Morris I. \& Wensley C.D., "Adams Operations and 2-operations in -Rings", Discrete Mathematics, 50, (1984), 253-270.

[8] Neumann P. M., Stoy G.A. \& Thompsone E.C., "Groups and Geometry", Vol.I. The Mathematical Institute, Oxford, (1982).

[9] Rose J.S., “ A Course on Group Theory”, Cambridge University Press, Cambridge, (1978).

[10] Solomon L., "The Burnside Algebra of a Finite Group", J. Combine. Theory 2, (1967), 603-615.

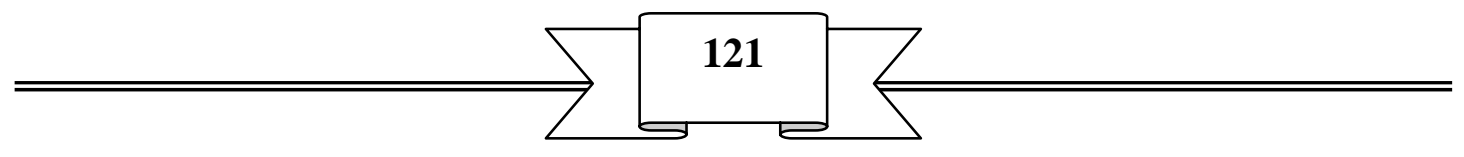

